ISSN 1518-3483

Licenciado sob uma Licença Creative Commons

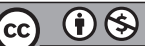

\title{
O cinema como componente didático da educação ambiental
}

\section{Cinema as didactic component of environmental education}

\author{
Fernando Zan Vieira ${ }^{[a]}$, Ademir José Rosso $^{[b]}$ \\ [a] Bacharel em Direito e Licenciado em História, Mestre em Educação pela Universidade Estadual de \\ Ponta Grossa (UEPG), Ponta Grossa, PR - Brasil, e-mail: vonstolzing@yahoo.com.br \\ [b] Licenciado em Ciências e Biologia, Doutor em Educação pela UFSC, professor da Licenciatura de \\ Biologia e do Programa de Pós-Graduação em Educação da Universidade Estadual de Ponta Grossa \\ (UEPG), Ponta Grossa, PR - Brasil, e-mail: ajrosso@uepg.br
}

\section{Resumo}

O artigo analisa a utilização do cinema na educação ambiental (EA). Discute-se a adequação dos filmes aos alunos e o papel mediador do professor ao propor atividades associadas a exibição de filmes na sala de aula. São apontados princípios para a utilização do cinema de impacto ambiental na promoção da EA, avaliação da recepção dos filmes, o aprendizado, a aquisição de novos valores ambientais e a mudança de atitudes. As informações obtidas e analisadas com os alunos participantes indicam o efeito positivo do cinema na aquisição de conhecimento, mudança de atitudes e valores diante do meio ambiente.

Palavras-chave: Cinema. Didática. Educação ambiental. 


\begin{abstract}
The article is an analysis about the utilization of cinema as didactic component of environmental education (EE). Is questioned the adequacy of the films for the students as well as the professor's role as mediator and challenger, by proposing activities associated to the exhibition of films in the classroom. Are highlighted the principles for the use of environmental impact cinema in the promotion of the EE, the evaluation of the reception of the movies, the learning, the acquisition of new environmental values and the changing in the behavior. The information that was analyzed indicate a positive effect in the acquisition of knowledge, of the change of attitudes and of the values.
\end{abstract}

Keywords: Cinema. Didactics. Environmental education.

\title{
Introdução
}

O cinema, por ser um elemento que reproduz e atua na formação da cultura da sociedade (DEBORD, 1997; METZ, 1972; TURNER, 1997), não pode ser ignorado pela Educação. Nesse sentido, pesquisas educacionais são feitas para desvelar tanto suas interferências (SILVEIRA, 2009) quanto suas potencialidades educativas (FERRO, 1992; MONTEIRO, 2005; NAPOLITANO, 2009). Da mesma forma têm sido pesquisadas e analisadas as produções cinematográficas para a educação ambiental (EA) (SAVVA; TRIMIS; ZACHARIOU, 2004; SILVA; KRASILSHIK, 2007).

A Didática assumida em sua multidimensionalidade articula as dimensões técnica, humana e política, não apenas como um elemento técnico no ensino. Essas dimensões se exigem reciprocamente e necessitam ser intencionalmente buscadas (CANDAU, 1985; ROSSO, 2007a) e retiram toda possibilidade de que o cinema, por si só, seja capaz de promover o desenvolvimento da EA crítica, pois uma perspectiva crítica e social necessita ser simultaneamente estruturada pelo conteúdo de ensino, pelo contexto histórico-social e a subjetividade do aprendente que permeiam a prática pedagógica (CANDAU, 1995). 
Dessa forma, os conhecimentos específicos presentes num filme sobre o ambiente, como por exemplo, aquecimento global ou efeito estufa, são tão estruturantes do percurso educativo quanto a sua forma de apresentação e os sujeitos envolvidos na experiência. A visão integrada e relacional conteúdo-forma exigem que a organização dos aspectos didáticos considere também o domínio dos conteúdos, e por extensão, a lógica interna dessa área de conhecimento. Conteúdo-forma relacionados e articulados no contexto social e histórico contribuem na estruturação da dimensão político-social do ambiente, não para sua visão naturalizada, mas crítica.

A EA para ser crítica necessita problematizar o contexto social e histórico, os valores presentes nas práticas e relações sociais, se expressar em atitudes e comportamentos concretos em permanente debate (LOUREIRO, 2005). Desprende-se disso que trabalhar a EA em seu sentido crítico necessita ultrapassar os patamares dos conhecimentos escolarizados e se inserir no contexto da vida dos alunos (ROSSO, 2007b) e das relações sociais. Os elementos estruturantes da Didática (CANDAU, 1995) podem ser mais bem explicitados para atender os objetivos da EA se englobam o conteúdo, as metodologias, os sujeitos, os contextos e mais a lógica desse conteúdo e os valores sociais e ambientais presentes nas relações humanas com o ambiente (ROSSO, 2007a, 2009).

Esses elementos estão assim explicitados por Rosso (2009):

1) conteúdos: a estrutura e a constituição interna das informações de diferentes áreas de conhecimento sobre o meio ambiente, segundo as especialidades destas áreas;

2) por metodologia: atende-se o ponto de vista da organização nas atividades de ensino e de $\mathrm{EA}$, dos elementos necessários e inerentes ao ato de aprender as noções/conteúdos sobre o ambiente/natureza;

3) sujeito da aprendizagem: envolvendo a atividade do sujeito no ato de conhecer segundo uma organização cognitiva, subjetividade e história pessoal;

4) contexto: onde se dá a prática pedagógica, os fins da educação, o caráter histórico-social da prática pedagógica e da educação; 
5) lógico: destaca a organização lógica do processo ensino-aprendizagem nos seus aspectos mais gerais e da própria produção histórica do conhecimento;

6) valores: as relações, interesses e com suas necessidades do homem social, apreendidos nas ênfases e omissões.

Como nesse texto pretende-se focalizar os avanços em atitudes e valores na EA, mediante a utilização didática do cinema no contexto de sala de aula, destacam-se os valores. Valor expressa as relações e interesses do homem social, com seus interesses e com suas necessidades, não sendo possível a existência de valores em si, de objetos puros ou autorreferventes (VÁSQUEZ, 2002, p. 141). A EA pensada como atitudes e valores dos humanos/alunos necessita voltar-se para o tipo de relações entre os humanos em suas ações diretas e indiretas com o ambiente e que repercutem no ambiente como um todo (SAUVÉ, 2005). Assim, o cinema na sala de aula, como instrumento didático, na construção da EA crítica, necessita buscar a transformação de atitudes e valores dos alunos diante do meio ambiente.

A hipótese que conduziu a investigação é a de que ao assistirem aos filmes, os alunos podem aprender e interpretar a presença do ser humano no ambiente, suas formas de interações e impactos e, também, proporem alternativas para que a vida na Terra não se torne inviável. Completando essa hipótese do ponto de vista da construção do conhecimento e do desenvolvimento de atitudes e valores ambientais críticos, compete ao professor problematizar a experiência, para que os alunos possam construir valores de cuidado do ambiente.

Para contribuir e convalidar as discussões são trazidas informações coletadas na projeção e debates de filmes com os alunos de $5^{\mathrm{a}}$ e $6^{\mathrm{a}}$ séries de uma Escola Estadual paranaense. São apresentadas informações sobre a recepção e o aprendido com os filmes e valores assumidos e atitudes tomadas a partir da experiência de aprendizagem. As informações foram obtidas mediante questionários aplicados em diferentes momentos das atividades e entrevista focal com grupo de alunos meses após a exibição e debate dos filmes. 


\section{Cinema na sala de aula}

A simples exibição do filme sem problematização e o debate com os alunos não atende aos requisitos educativos e críticos. Para desempenhar seu papel na promoção da EA, o cinema necessita atender a faixa etária dos alunos que assistirão ao filme e ser relevante ao que se pretende ensinar associados a mediação do professor trazendo informações que contextualizem o encaminhamento de questões que liguem o filme à ciência e às ações humanas. A mediação do professor necessita desafiar os alunos, fazer as perguntas, confrontar contextos, buscar e debater questões sobre o filme.

O conteúdo do filme necessita ser adequado e relevante ao que se pretende ensinar e à disciplina de ensino. Trata-se de aproximar o conteúdo do filme (que constituirá a aula) com a matéria de ensino. Outro cuidado diz respeito à faixa etária dos alunos, por isso é importante saber se as imagens exibidas realmente são próprias para idade, estádio cognitivo e compreensão dos alunos. Esses cuidados são necessários para que o poder da mídia em "atuar sobre o público espectador, fazendo-o ver como possíveis as histórias e representações” (SILVEIRA, 2009, p. 178) tragam novas possibilidades do real.

Isso envolve aspectos metodológicos, para favorecer o aluno pensar e agir sobre as imagens assistidas, e para que, "de modo independente e autônomo, aprendam a buscar, selecionar e interpretar as informações disponíveis" mediante a crítica (FRESCHI, 2008, p. 156). Para desafiar o aluno e buscar a crítica e o debate a exibição do filme necessita ser antecedida de indagações acerca do tema, visando o seu interesse e disposição em aprender por meio do filme. A participação e envolvimento dos alunos a partir das imagens assistidas é fundamental na superação do conhecimento cotidiano pela construção de conhecimentos cada vez mais complexos e com características mais científicas. Dito isso, o cinema na sala de aula não pode ter a função meramente de ilustrar, mas de permitir ao aluno construir leituras e possibilidades por meio dos filmes que assiste.

De espectador necessita passar para protagonista e construir sua própria história a partir da avaliação do que assistem. A experiência 
com os filmes pode resultar numa armadilha não raro frequente, pois "as imagens e os movimentos sonorizados do cinema e da televisão têm um grau forte de realidade. Realidade no sentido de que aquilo que a pessoa está vendo 'é', mais do que 'parece ser"' (ALMEIDA, 1994). Sem os cuidados iniciais e o debate a experiência torna-se pobre, e com pouco significado para a aprendizagem crítica.

Um engano comum é considerar a imagem do filme como sendo a verdade final e derradeira do tema narrado. O desafio a ser posto para aluno está na abertura para novas interpretações e possibilidades para a vida a partir do filme. Assim, o cinema atingiria de forma bastante plena suas possibilidades educativas (RODRIGUEZ, 2009, p. 139):

1) [...] educa na contemporaneidade, nas questões que nos ocupam e nos preocupam; 2) ativa o conhecimento, descobrindo de maneira lúcida aquilo que antes não havíamos reparado; 3) estabelece relações com a realidade que resultam mais imediatas, porém, igualmente, com aquelas que estão distantes; 4) [... obtém-se] ao invés de respostas um sem número de perguntas, sendo o motivo para aprender; 5) [capacita] pensar e contribuir em um novo discurso inspirado no diálogo e na necessidade de seguir aprendendo através da investigação.

Compreendendo que a ação educativa é sobretudo construção e transformação de valores, a ser buscada com perguntas que desafiam o aluno a continuar pesquisando, a construção de valores e hábitos, como a proteção ambiental, mesmo que seja difícil comprovar, não se pode ignorar que "os filmes produzem opiniões e comportamentos" (SILVEIRA, 2009, p. 178). O filme tem então um forte potencial de transformação e de construção de novas possibilidades. A produção cinematográfica "é uma produção que segue objetivos bem definidos, fins a serem alcançados, hábitos comportamentais a serem modificados e hábitos intelectuais a serem conservados (ALMEIDA, 1994, p. 14). E nisso ela se parece com a escola e a escolha correta e adequada do filme a ser utilizado na sala de aula pode contribuir na construção de valores de cidadania, democracia, autonomia e independência, para que o aluno seja educado considerando 
sua posição no mundo e a posição da coletividade como seus iguais, também sujeitos de direitos.

Assim, o filme como elemento didático pode completar, mas não aliviar ou substituir a atividade do professor. Levantar questões para serem pesquisadas e discutidas, bem como encaminhar o aprendizado significativo dos alunos, exige estudo e planejamento do professor. Importa que a curiosidade seja provocada para que o aluno preste atenção ao filme e pense questões que promovam a ação em direção ao conhecimento. Trabalhar com o cinema "em sala de aula é ajudar a escola a reencontrar a cultura ao mesmo tempo cotidiana e elevada, pois o cinema é o campo no qual a estética, o lazer, a ideologia e os valores sociais mais amplos são sintetizados numa mesma obra de arte" (NAPOLITANO, 2009, p. 11-12). Não se trata de pensar o cinema como uma solução milagrosa e definitiva para questões educacionais, mas como uma opção que deve ser tratada com a devida seriedade, sob pena de comprometer a prática didática.

No que diz respeito à educação ambiental, o professor pode procurar filmes e documentários que abordem assuntos como a poluição atmosférica, o efeito estufa, o desmatamento, o aquecimento global e a poluição das grandes massas de água, tais como oceanos, mares e rios. Eventos de impacto contra a vida animal no planeta, tais como a caça predatória e a destruição dos habitats naturais são outros exemplos que podem ser trabalhados na sala de aula por meio do cinema.

O cinema, como recurso moderno e atrativo traz para a prática pedagógica aquilo que a escola se "nega a ser e que poderia transformá-la em algo vívido e fundamental: participante ativa da cultura e não repetidora e divulgadora de conhecimentos massificados, muitas vezes já deteriorados, defasados" (NAPOLITANO, 2009, p. 12). O cinema tem o potencial de atrair e de chamar a atenção, de provocar reações no espectador, de amor, ódio, alegria, indignação. Portanto, se a prática do professor for bem planejada, pode transcender o limite do puro entretenimento e permitir a construção da consciência e do juízo crítico. Assim, a vida social, econômica, política, bem como os sistemas de valores que a fundamenta, podem ser revelados "por formas e práticas aparentemente efêmeras 
como televisão, rádio, esportes, histórias em quadrinhos, cinema, música e moda" (TURNER, 1997, p. 48).

Procurando fazer com que o aluno reaja ao evento apresentado pelo filme, podemos ter que, dentre os aspectos, "um dos mais importantes é o da impressão de realidade vivida pelo espectador diante do filme" (METZ, 1972, p. 16). A imagem do filme tem potencial para "introduzir um novo assunto, para despertar a curiosidade, a motivação para novos temas. Isso facilitará o desejo de pesquisa nos alunos para aprofundar o assunto do vídeo e da matéria" (NAPOLITANO, 2009, p. 34). Aliado ao conteúdo do livro didático e sem prejuízo de outros materiais eventuais, o cinema pode ensinar de forma eficaz, porém o alerta permanente, cabe ao professor buscar a melhor situação para utilizá-lo e apresentá-lo aos alunos.

\section{Modalidades de cinema}

O cinema, tomado em sentido amplo e geral pode ser dividido em duas categorias para fins didáticos: comercial e documentário. Para efeito de terminologia, empregamos para o primeiro tipo a expressão "filme" e para o segundo "documentário". O filme se caracteriza por contar uma história. Nos países ocidentais, esse tipo de filme tem em Hollywood o centro produtor e lançador de títulos por saturação em épocas específicas, em geral nos feriados de verão (julho-agosto) e de Natal (dezembro) no hemisfério norte. As características gerais dos seus filmes, salvo exceções, são segundo Mascarello (2006, p. 340) as de apresentar:

personagens bem definidos e com objetivos claros; as ações linearmente organizadas no que tange a causa e efeito; a unidade de ação, tempo e espaço no interior de cenas e sequências; a subserviência do estilo às necessidades de exposição da história; e a comunicabilidade e a redundância.

Se o filme for pensado como elemento reprodutor de uma realidade sobre a qual se estuda, o professor necessita atentar para a qualidade, 
a relevância e a confiabilidade das informações e eventos trazidos. Os filmes comerciais são um produto tecnológico colocado à venda, e como todo espetáculo, procura atrair pela estética, deixando em segundo plano o conteúdo. Poderemos encontrar "a tão evidente perda da qualidade, em todos os níveis, dos objetos que a linguagem espetacular utiliza e das atitudes que ela ordena [...] (e) afasta a realidade" (DEBORD, 2008, p. 28). É a principal limitação dos filmes comerciais.

A sua produção, segundo uma concepção industrial voltada para a diversão e o entretenimento, apresenta uma organização narrativa que deixa para seu auditório pouco espaço de interpretação. Se o filme procura mais divertir do que ensinar, mais calar do que levantar questões apresenta sérias limitações ao propósito educativo. Podemos identificar inclusive a existência de uma "impressão de realidade, fenômeno de muitas consequências estéticas, mas cujos fundamentos são sobretudo psicológicos" (METZ, 1972, p. 17). Nisso está o perigo da "sedução do espectador" praticada pela imagem em movimento, levando a efeitos emocionais, em que a "realidade cuja imagem é oferecida pelo cinema parece terrivelmente verdadeira" (FERRO, 1992, p. 85).

O cinema de ficção traz em si pouca independência crítica, exigindo a sua "desconstrução" pelo professor ao apresentá-lo aos seus alunos, separando fato da ficção, podendo e devendo servir-se de algum material de apoio. Uma bibliografia específica, pode ajudar a responder o que pode ser considerado fato, e o que é dramatização para fins narrativos. Os cuidados do professor têm início com a escolha do filme, pois os filmes comerciais não conseguem escapar do cinema de espetáculo. Por vezes, apresentam uma história qualquer sobre o bem e o mal, com partes bem definidas, sem a possibilidade de problematização ou controvérsia. Sem controvérsia não há debate, e sem discussão tem-se a aceitação inquestionável dos eventos, impossibilitando a compreensão dos conteúdos em nome do espetáculo (a forma!) e a aceitação de diferenças. Sem respeito às diferenças, não há democracia. Mesmo assim, ao proporcionar ao aluno a possibilidade de integrar à cognição de um objeto de estudo, mediado pela ação docente, pode torná-lo válido como elemento didático. O cinema 
de ficção não precisa ser descartado, imaginando que não contém verdade alguma e que não deriva de projeções do presente.

O documentário, como seu próprio nome sugere possui maior proximidade com a "realidade". Sua utilização tem o potencial de aproximar um pouco mais o aluno da realidade, mais do que apenas a representação parcial, condensada ou fragmentada dos filmes comerciais. Como representação da realidade, o documentário procurou um conceito próprio "no campo das ciências humanas, para designar um conjunto de documentos com a consistência de 'prova', a respeito de uma época". Pretendendo ser uma exposição filmada quase objetiva da realidade, buscando mostrar "as coisas como de fato ocorreram". O documentário traz em si "uma forte conotação representacional, ou seja, o sentido de um documento histórico que se quer veraz, comprobatório daquilo que 'de fato' ocorreu num tempo e espaço dados” (TEIXEIRA, 2006, p. 253).

O potencial do documentário está em oferecer ao aluno que o assiste uma oportunidade de observar o próprio fato, ou talvez de retirar impressões mais diretas dele, o que poderia ajudar no processo educativo. O documentário pretende ter por conteúdo um "olhar verdadeiro e científico sobre o tema ou questão retratada” (NAPOLITANO, 2009, p. 31). Não se pode sucumbir à ingenuidade de imaginar que uma produção possa vir a ser absolutamente objetiva e imparcial, pois se trata de "um dos gêneros de filme (produzido para o cinema, vídeo ou televisão) mais utilizados pelo professor em sala de aula e projetos escolares" (NAPOLITANO, 2009, p. 30-31). Adverte o autor sobre os filmes que trabalham o meio ambiente podem ser portadores de abordagem "superficial e excessivamente romântica, válida para a consolidação de valores ecológicos, mas pouco explicativas da complexidade política, econômica e social do problema da agressão à natureza".

Como o documentário não é um modelo perfeito de cinema, como nenhum pode ser, cabe ao professor tomar tanto o filme quanto o documentário como um "começo de discussão e aprofundamento do tema" (NAPOLITANO, 2009, p. 54). Deve-se cuidar, em qualquer dos casos após assistir aquilo que lhe foi apresentado, o espectador não pode incorrer 
no erro de assumir que tudo ocorreu "de verdade" no "mundo dos fatos" (no cinema de ficção) ou que aquela é a única e definitiva representação da realidade, sem qualquer outra possibilidade (no documentário). Por isso, "o professor deve evitar partir do princípio de que a abordagem dada pelo documentário é a única possível ao tema retratado ou que o conteúdo mostrado é a realidade social ou a verdade científica sobre o assunto" (NAPOLITANO, 2009, p. 31).

Desde muito, o documentário disputa com a "ficção essa prerrogativa de representação da realidade e, consequentemente, de revelação da verdade" (TEIXEIRA, 2006, p. 253). Mas como acontece no filme comercial, o documentário é produto cultural de um grupo social específico, que contém uma mensagem e uma visão de mundo destinada para o seu próprio e para outros grupos sociais. Essa mensagem terá conotações não apenas sociais, mas também políticas e econômicas, legitimando ou deslegitimando um evento, um acontecimento, ou mesmo outro grupo social. ${ }^{1}$ Portanto, temos já presente um limite imposto quanto à utilização de documentários. Não podemos cair na tentação de "imaginar o filme documentário como a expressão legítima do real ou [...] crer que ele está mais próximo da verdade e da realidade do que os filmes de ficção" (BRASIL, 1995, p. 1). A visão social da realidade, qualquer que seja ela, é específica e nunca imparcial. Mais do que ser utilizado para retratar ou reproduzir a realidade, o documentário e o filme convergem eventualmente como instrumentos culturais de construção da realidade.

O filme e o documentário têm outros pontos em comum, próprios da ciência cinematográfica: roteiro, montagem, direção, som, dentre outros. Pensando apenas na simples técnica de montar a sequência documental, podemos imaginar que essa manipulação da imagem "contradiz, evidentemente, o pensamento ou a suposição de que tudo que se assiste em um filme documentário pode ser encarado como verdade" (BRASIL, 1995, p. 2-3). As duas modalidades não são neutras, quanto ao conteúdo

1 Vide por exemplo os documentários de exaltação do Nazismo, como $O$ triunfo da vontade (Triumph des Willens, 1935) e Olympia (Olympia, 1938), ambos de Leni Riefenstahl. 
e nem quanto à forma do que apresentam. Por mais próximo que se possa chegar diante de uma suposta neutralidade sobre a apresentação e descrição do objeto narrado pela imagem, essa neutralidade nunca será absoluta. Os filmes são produzidos em tempos e momentos distintos, para públicos diversos, segundo códigos sociais, valorativos e comportamentais que variam no tempo e no espaço, e que estão em constante mudança. Basta uma análise rápida das produções contemporâneas em comparação com outras mais antigas como comprovação. Afinal, o filme sempre será "uma equivalência àquilo que o conjunto da sociedade pode ser e fazer" (DEBORD, 2008, p. 34).

No entanto, o cinema pode atingir fins educativos, uma vez que "tem essa capacidade de desestruturar aquilo que diversas gerações de homens de Estado e pensadores conseguiram ordenar num belo equilíbrio". Dado o caráter crítico da EA é bastante apropriado, pois o filme poderia apresentar "o avesso de uma sociedade, seus lapsos" (FERRO, 1992, p. 86). E no que se refere à EA propriamente dita, levada a efeito por meio do cinema, vale o alerte de que "a problemática ambiental demanda a produção de um corpo complexo e integrado de conhecimentos sobre os processos naturais e sociais que intervêm em sua gênese e em sua resolução" (LEFF, 2001b, p. 162). O uso das novas tecnologias na EA cria a "necessidade de enfoques integradores do conhecimento para compreender as causas e a dinâmica de processos socioambientais que [...] exig(em) uma recomposição holística, sistêmica e interdisciplinar do saber" (LEFF, 2001a, p. 147).

Uma meta para a utilização do filme de impacto ambiental é a construção de valores, dentro do contexto escolar. Assim, procura-se ensinar valores que permitam a adoção de uma postura crítica e ativa, que possa ir além do conhecimento puro e simples do problema, pois "a aprendizagem ambiental transformadora pode se beneficiar da emergência de novos conceitos e métodos das disciplinas ambientais e da elaboração de métodos pedagógicos para a transmissão do saber ambiental" (LEFF, 2001b, p. 164).

Dessa forma podem ser promovidos valores que permitam a ação no mundo onde o aluno vive por meio da formação de uma postura pessoal, autônoma e independente sobre os problemas ambientais. Os temas presentes nos filmes de impacto ambiental ao serem escolhidas pelo 
professor dentro dessa perspectiva priorizam as "informações que, longe de provocar um imobilismo pela perspectiva catastrófica, possam favorecer a capacidade de construção de valores éticos, bem como de responsabilidade e participação" (SILVA; KRASILCHIK, 2007, p. 7).

\section{O cinema de impacto ambiental e sua utilização na educação ambiental}

A utilização do cinema demonstra como "é importante a criação de mecanismos que possibilitem identificar concepções de EA de livros, materiais didáticos, vídeos, filmes, programas de televisão, entre outros" (SILVA; KRASILCHIK, 2007, p. 3). Os filmes com temática ambiental podem permitir um processo educativo efetivo na sala de aula garantindo que cada "mecanismo da escola tenha formulado uma atitude responsável em direção de um desenvolvimento sustentável do Planeta Terra” (BELL, 2004 , p. 37). Dessa forma, atitudes e valores ambientais podem ser problematizados pela apresentação de filmes de impacto ambiental, teorizada na direção da construção de conhecimentos, de valores e de criticidade dos alunos. Para tanto, analisamos duas concepções de educação ambiental vigentes, a Conservadora e a Crítica, e sugerimos alguns filmes que podem ser utilizados em defesa de uma educação voltada para a segunda corrente.

Para a corrente Conservadora ou Comportamentalista, o problema ambiental é apenas parte de um processo histórico transitório e facilmente contornável. A crise ambiental é simplificada, ao acusar o cidadão comum da responsabilidade pela degradação ambiental. Independente da posição social do indivíduo, todos são igualmente culpados e dividem a mesma parcela de responsabilidade pelos eventos de impacto ambiental. Evidentemente, “a própria complexidade dos problemas ambientais e suas repercussões econômicas, políticas e sociais fazem com que esta simplificação do processo de formação ambiental resulte ineficaz" (LEFF, 2001a, p. 223).

Para essa corrente, a educação ambiental tem uma dimensão individual e dissociada da coletividade e a crise ambiental é reversível pela conscientização individual. A noção transformadora da realidade é 
substituída por uma visão mística e transcendente da realidade e a EA torna-se um processo despolitizado e independente da ação daqueles que detêm o poder: o culpado é o cidadão comum. Critica-se nessa visão a repulsa aos princípios da solidariedade social, do respeito à diversidade cultural, da dignidade da vida humana e da democracia participativa, que são trivializados e simplificados, "reduzindo a educação ambiental a ações de conscientização dos cidadãos e à inserção de 'componentes' de capacitação dentro de projetos orientados por critérios de rentabilidade econômica" (LEFF, 2001a, p. 223). Tais princípios são substituídos por uma "cultura do poder fundado na razão tecnológica e na racionalidade econômica” (LEFF, 2001a, p. 87), uma vez que não se questionam os processos históricos de ocupação e uso da terra e a utilização do meio ambiente de acordo com os interesses privados.

Essa corrente não faz indagações sobre os interesses consumistas e comerciais humanos, para a qual bastaria uma diminuição quantitativa dos bens de consumo, especialmente aqueles de origem natural, permanecendo inalterada a produção, circulação e acesso a esses bens. Não se problematiza quem produz e para quem é produzido, sob quais circunstâncias, em razão de quais interesses, e quem realmente tem a possibilidade econômica de produzir, consumir e fazer circular os produtos de consumo. Outro problema desta visão está na dissociação da dinâmica sociedade-natureza. As dimensões sociais humanas se perdem dentro de uma dimensão puramente natural, e a questão da sobrevivência da espécie humana como grupo coletivo passa a ocupar lugar de menor importância. O responsável pela degradação ambiental está fora da realidade: todos são responsáveis ao mesmo tempo em que ninguém é. Não há a preocupação de se apontar os responsáveis pelos abusos cometidos contra o meio ambiente, o que seria também uma acusação aos atores sociais de maior expressão no poder político e econômico. Convenientemente, a visão conservadora deixa de se ocupar de questões de maior reflexão acerca da posição social e dos papéis políticos.

Em oposição a esta visão, a corrente crítica traz por fundamento a emancipação e a autonomia do ser humano. Para que o ser humano 
seja verdadeiramente livre, o ser humano deve saber como se definir e como definir sua relação com o meio ambiente, se esta será de cooperação ou de apropriação irresponsável. Essa abordagem educativa poderia redefinir a forma como os seres humanos, especialmente em suas relações econômicas, se posicionam diante dos demais indivíduos de sua própria espécie, bem como diante de todas as espécies e ecossistemas com os quais dividimos o planeta. Dessa forma, "a consciência ambiental se coloca como consciência de todo o gênero humano, convocando todo indivíduo como sujeito moral para construir uma nova racionalidade social" (LEFF, 2001a, p. 92).

O enfrentamento dos problemas ambientais necessita do debate e enfrentamento público e politizado, pois "o saber ambiental se constitui por meio de processos políticos, culturais e sociais, que obstaculizam ou promovem a realização de suas potencialidades para transformar as relações sociedade-natureza" (LEFF, 2001a, p. 151). Essa corrente de EA busca compreender as relações econômicas e sociais que causam a degradação ambiental, essencialmente por meio do contexto histórico de dominação e apropriação dos bens naturais. Analisa a produção, distribuição, acesso e consumo desses bens, bem como a ética e os valores subjacentes as ações. A EA crítica é essencialmente transformadora: "a dialética forma e conteúdo deve se realizar de tal maneira que as alterações da atividade humana, vinculadas ao fazer educativo, impliquem mudanças individuais e coletivas" (LOUREIRO, 2005, p. 1484).

O uso de novas tecnologias pode permitir a interação do sujeito com "uma determinada estrutura de informação, que vem gerar uma modificação em seu estado cognitivo, produzindo conhecimento, que se relaciona corretamente com a informação recebida" (BARRETO apud TAVARES; FREIRE, 2003, p. 126). Nada impede que essa estrutura de informação consista na imagem transmitida pelos filmes, com os quais os alunos possam interagir e adquirir novos conhecimentos. A informação científica que permeia a EA pode vir de meios tecnológicos como o cinema, podendo ser vista como "dados, informações, metodologias e processos de representação, reflexão e transformação da realidade”, e que, também, contribuem 
para a "compreensão, análise e interação harmônica dos elementos naturais, humanos e sociais” (TAVARES; FREIRE, 2003, p. 126).

Entendendo que a prática de se assistir a um filme envolve um exercício de interpretação, a utilização do cinema na sala de aula não pode ser baseada em um modelo único. Pois os materiais didáticos baseados nas novas tecnologias são mais complexos, e não possuem uma linguagem estável, impedindo a cristalização de "modelos de sucesso" (RODRIGUES; COLASANTI, 2008, p. 53). Não obstante, qualquer professor com um mínimo de consciência deve saber escolher qual o filme ou documentário mais adequado à sua prática, de forma a tornar a experiência interessante aos alunos. Além de despertar o interesse, por meio das imagens veiculadas, o cinema pode também despertar o raciocínio, tornando a aprendizagem mais prazerosa e, possivelmente, mais eficiente (OLIVEIRA; NASCIMENTO; BIANCONI, 2005, p. 47). Dessa forma, o cinema como um meio didático de expressão mais moderno, ligado aos avanços tecnológicos pode ajudar "a compreender os problemas ambientais, mobilizar-se e comprometer-se com a tomada de decisões voltadas à melhoria da qualidade de vida, implicando uma responsabilidade ética/social e justiça ambiental" (RODRIGUES; COLASANTI, 2008, p. 54).

O cinema de impacto ambiental pode apresentar informações que despertem o interesse dos alunos e permitem a tomada de atitudes que provoquem a transformação ambiental na sua própria realidade. A percepção do problema ambiental e de suas possíveis formas de resolução pode e deve ser tomada pelos próprios alunos, permitindo-lhes que se tornem independentes e críticos, para serem agentes transformadores do seu ambiente. Por meio do conteúdo dos filmes de impacto ambiental, podemos adentrar aos problemas ambientais presentes em suas narrativas. São perceptíveis na narrativa dos filmes problemas de agressão contra o meio ambiente que já acontecem há algum tempo e produzem sua naturalização. Isso gera certa sensação de insolubilidade ou de normalidade dos problemas ambientais, promovendo a acomodação, ao invés da tentativa de solucioná-los. Como outras formas de informação, os filmes 
constituem um ponto de partida para a educação no sentido de realmente tentarmos debater soluções aos desafios ambientais.

Iniciado na Revolução Industrial, o aquecimento global é o processo que produz o aumento da temperatura média dos oceanos e do ar perto da superfície do planeta, diminuindo as coberturas naturais de gelo e aumentando os níveis dos mares, causando uma mudança drástica nos padrões climáticos. Sua causa é a absorção excessiva de calor na atmosfera, o que ocorre por meio do aprisionamento desse calor por alguns gases como o dióxido de carbono, metano, óxido nitroso e os clorofluorcarbonos. O aumento desses gases na atmosfera é causado pelos seres humanos, podendo chegar a um ponto em que todas as formas de vida do planeta estejam ameaçadas de extinção em documentários como A última hora (2006) e os efeitos desastrosos para a espécie humana podem ser conferidos no filme O dia depois de amanhã (2004).

Outro processo que contribui muito para o efeito estufa é o desmatamento. Esse processo é fundamentalmente definido como o desaparecimento das massas florestais, causado principalmente pela ação humana. A destruição de florestas está ocorrendo para a obtenção da terra para fins agrícolas e pecuários e para a extração de madeira, o que acontece muitas vezes de forma irresponsável e ilegal. E como as plantas têm por função a absorção de gases como o dióxido de carbono, o desaparecimento das florestas favorece o crescimento do efeito estufa e, em consequência, aumenta também o aquecimento global. Dentre os títulos, encontramos o documentário brasileiro Mudança de clima, mudança de vidas (2006), produzido pelo grupo ambientalista Greenpeace, sendo um título que pode ser apresentado na sala de aula.

A poluição da água é outro evento ambiental onde a ação destruidora do homem tem sido a grande responsável. O homem atua poluindo a água por meio da contaminação de massas como rios e mares, prejudicando as formas de vida que são naturais desses espaços; vários tipos de dejetos produzidos por fábricas são alguns dos agentes mais comuns. A poluição do ar causa alterações atmosféricas provocadas pela emissão de gases ou pelo uso de energia pelas indústrias. O desenho animado 
longa-metragem Os Simpsons: o filme (2007) é especialmente adequado para o trabalho com crianças.

O problema da poluição da água é temática fundamental do filme Erin Brokovich: uma mulher de talento (2000), que trata do processo litigioso movido por uma advogada contra uma empresa poluente de fontes de água, cuja ação teve por consequência a ocorrência de casos de câncer em grande parte da população, por meio do consumo de água contaminada com bromo. O filme também promove a discussão e o posicionamento político, favorecendo a tomada de atitudes e a vontade de mudanças.

Os filmes favorecem a discussão dos problemas ambientais, podendo ser usados no processo educativo para promover o compromisso com o meio ambiente. Os filmes voltados para a EA podem subsidiar a temática de que a destruição do meio ambiente é a destruição dos ecossistemas e as formas vivas que nele habitam. Mais do que a conservação e o respeito ao planeta, uma das grandes preocupações da EA é a garantia de um mundo habitável para nossas gerações futuras.

\section{O filme na sala de aula: recepção, aprendizado, aquisição de valores e mudança de atitudes}

As informações apresentadas são de natureza qualitativa e traduzem as respostas dadas pelos alunos. Nelas pode-se identificar além da recepção positiva ou negativa da experiência, se houve aprendizado ambiental, aquisição de novos valores e transformação das atitudes dos alunos diante do meio ambiente.

Quanto à recepção, as respostas indicam que a experiência teve boa aceitação e trouxe resultados positivos. O uso de filmes sobre o meio ambiente é importante porque deu uma noção do que é a natureza. É indicada a urgência do problema ambiental, como evento real: o filme foi importante, porque fala de um problema que talvez nós tenhamos no futuro, e todo mundo tem que colaborar [...]; os professores ao passarem filmes para a gente, fez com que todo mundo aprendesse. Dessa forma, "não se trata de ver um 
filme como simples espectador; a educação ambiental trata de torná-lo protagonista, ou por sua vez diretor, ou vice-versa" (RODRIGUEZ, 2009, p. 134). Colocando o aluno no centro do problema, a possibilidade dele se interessar e buscar aprender pode aumentar consideravelmente.

O aprendizado proporcionado por meio dos filmes foi citado várias vezes pelos alunos: muitos deles respondem de forma direta: $o$ filme foi importante para aprender mais, ficar mais informada sobre aquecimento global, eu quis aprender mais. Com o aprendizado obtido por meio do cinema na sala de aula, são obtidas mudanças de atitudes: aprendi a não jogar lixo, guardar material reciclável, pois não podemos jogar tudo fora, desperdiçar luz, energia. A temática trazida pelos filmes ajudou a chamar a atenção para os problemas ambientais: eu achei interessante o filme porque estou aprendendo sobre o aquecimento global. Vê-se assim que "o cinema que educa é um espetáculo sem precedente que convoca a um número considerável de espectadores levados pela inquietude e intenção de ver e escutar na tela uma história contada na forma audiovisual" (RODRIGUEZ, 2009, p. 139).

O novo aprendizado é acompanhado muitas vezes de novos valores; além de adquirir conhecimento, o aluno passa a adquirir valores morais: o sol pode derreter geleiras e pode inundar várias cidades; devemos impedir porque temos que cuidar do nosso planeta; Os raios solares entram na Terra e quando vão sair, os gases do efeito estufa fazem uma barreira e não deixam os raios solares saírem, e então acontece o aquecimento global. Eu aprendi que é muito perigoso e temos que tentar evitar, para não morrermos. Considerando o hipertexto no qual pode consistir o cinema, as descrições dos alunos indicam como "as imagens são, às vezes, mais fortes do que um texto" (ALMEIDA, 1994, p. 9).

A relação entre aprendizado e transformação de atitudes, intermediada pela aquisição de novos valores de proteção ambiental surge conectada nas respostas dos alunos. Enquanto se aprende os valores de responsabilidade ecológica se materializam em atitudes práticas. Os alunos respondem que o filme nos ensinou a preservarmos o meio ambiente, jogar lixo no lixo e a cuidar do meio ambiente. O próprio aluno se coloca como 
vítima do problema, e compreende as consequências das ações de degradação ambiental: devemos impedir o aquecimento global para não morrermos de tanto calor; o filme mostrou que seremos prejudicados se nós mesmos não pararmos de poluir o ar, rios, lagos. A perspectiva dos alunos, a partir dos filmes, como parte desse mundo mostra como "o saber ambiental muda o olhar do conhecimento e com isso transforma as condições do saber no mundo na relação do que estabelece o ser com o pensar e o saber, com o conhecer e o atuar no mundo" (LEFF, 2009, p. 18).

A vontade de transformar e de resolver o problema promove corresponsabilidade. O aprendizado não se limita aos alunos, mas adquire projeção social, passando o problema a ser debatido no espaço familiar. A perspectiva social se irradia da escola, levando o aprendizado para as famílias dos alunos: passei a falar para as pessoas, irmã, pai, para não jogarem mais lixo nas ruas; valeu a pena; eu comecei a reciclar e já alertei a minha família para não jogar lixo na rua, não poluir. Dessa forma, o aluno se identifica com o problema ambiental e passa a agir como figura central na proteção da natureza. A importância de compartilhar o aprendido com a família está na resposta de outro aluno: minha avó jogava garrafa, tudo junto, daí eu falei para ela separar, lá em casa é tudo separado, lixo reciclável. Falei com minha mãe, pai, avô, avó, com a família.

O importante na experiência com os filmes é possibilitar que o aluno se compreenda como agente de modificação e transformação da sua realidade, por meio de suas próprias ações: tal qual a EA, "trata-se de um saber ao qual não escapa a questão do poder e a produção de sentidos civilizatórios" (LEFF, 2009, p. 19). O que ocorre é que esse saber e esses sentidos são integrados e colocados à disposição dos alunos a partir dos filmes. A importância está em desenvolver a autonomia e a independência nos alunos, para que possam modificar seus valores e em consequência, suas atitudes, compreendendo o seu papel na resolução do problema: podemos fazer muitas coisas, como cuidar do meio ambiente, não jogar lixo nos rios, não destruir árvores. Comecei a guardar caixa de leite, garrafa pet, passar para reciclagem e alertar a população para não destruir o meio ambiente. 
O filme revelou-se como um instrumento adequado e útil ao aprendizado, possibilitando além da aprendizagem do conteúdo, também a mudança de atitudes e a aquisição de valores de preocupação e proteção com o meio ambiente: o filme mudou muita coisa que eu não sabia sobre os perigos do meio ambiente. Agora eu tenho a consciência de que pode acontecer com nós. Todos nós temos que ter a consciência e ouvir todos que falam sobre isso. Os filmes foram importantes porque incentivaram a ajudar mais o meio ambiente. Tem-se uma transformação de valores, obtidos a partir da experiência com os filmes, que permitiram a construção de "sentidos coletivos e identidades compartilhadas que formam significações culturais diversas na perspectiva de uma complexidade emergente e de um futuro sustentável” (LEFF, 2009, p. 21).

\section{Considerações finais}

Procuramos demonstrar a possibilidade do uso de filmes como contribuição à atividade educativa na sala de aula a partir do cinema de impacto ambiental, tendo em vista a EA crítica. É de grande importância a escolha de produções cinematográficas voltadas aos problemas ambientais, apresentando filmes aos alunos que tratavam dos prejuízos causados diretamente pela ação humana.

Sendo assim, os usos de filmes na sala de aula mostram-se um bom recurso metodológico, enquanto ponto de partida. Para que o filme em si, como fonte de informações se transforme em interesse e objeto de conhecimento pelo aluno, e dele extraia conhecimento, o professor necessita criar situações que estimulem e desafiem o aluno a agir. Essa ação promovida, radicada na dinâmica da inteligência conduz a construção de conhecimentos operatórios junto com a tomada de consciência, promovendo valores e atitudes ativas de cuidado e defasa do ambiente.

O interesse provocado pelo filme, por meio de sua forte atração baseada no dinamismo da imagem em movimento e também pelo seu aspecto cultural, constitui-se num forte coadjuvante das iniciativas do 
professor para desequilibrar os alunos e provocar o dinamismo da inteligência do aluno na direção do conhecimento vivo, operante e capaz de dialogar com o ambiente concreto.

Quanto ao conhecimento, pretende-se promover a EA crítica, que permita que os alunos se coloquem diante do problema ambiental como sujeito/cidadão, politizado, democratizado e consciente de si e dos mecanismos de funcionamento do mundo, também o mundo social para construir mudanças significativas, que influam na melhoria do mundo e da qualidade de vida dos seres humanos. As informações levantadas durante a análise sobre a construção dos valores demonstram a potencialidade da fonte de informação escolhida e de seu encaminhamento teórico-metodológico como elementos que contribuem para a formação da cidadania nos alunos, constituída em um dos objetivos mais caros da educação ambiental.

Podemos defender a posição de que a exibição para os alunos de filmes sobre o impacto ambiental na sala de aula permite a identificação de novas atitudes, como o despertar da consciência na forma de preocupações voltadas para a proteção do meio ambiente, e a construção e defesa de novos valores, pelos quais os alunos possam ter elementos para tomar uma posição ativa na direção de mudanças efetivas em seu cotidiano.

A partir da utilização didática de filmes de educação ambiental na sala de aula. Apresentamos assim "uma tentativa de intensificar a percepção ambiental por meio de atividades artísticas experimentais" (SAVVA; TRIMIS; ZACHARIOU, 2004, p. 248). Pode-se dizer que "exibir filmes e documentários qualquer professor é capaz de fazer. Porém, a problemática está em criar condições que possam levar os alunos a um debate individual e em grupo" (MONTEIRO, 2005, p. 12). Importa para a EA "educar para que os novos homens e mulheres do mundo sejam capazes de suportar a carga desta crise civilizatória e convertê-la no sentido de sua existência" (LEFF, 2009, p. 24). O cinema, desde que devidamente problematizado, tem forte potencial educativo associado aos propósitos didáticos, e a EA, é o caso comprovado nessa pesquisa. 


\section{Referências}

ALMEIDA, M. J. Imagens e sons: a nova cultura oral. São Paulo: Cortez, 1994.

A ÚLTIMA hora (11th Hour). Produção de Leonardo DiCaprio, Leila Conners Petersen, Chuck Castleberry e Brian Gerber. Direção de Nadia Conners e Leila Conners Petersen. Estados Unidos, 2007. 1 DVD (95 min), color. son.

BELL, D. R. Creating green citizens? Political liberalism and environmental education. Journal of Philosophy of Education, v. 38, n. 1, p. 37-53, 2004.

BRASIL, U. O filme Documentário como "Documento da Verdade". 0 Olho da História, Salvador, v. 1, n. 1, p. 1301-139, 1995.

CANDAU, V. M. A didática e a formação de educadores - da exaltação à negação: a busca da relevância. In: CANDAU, V. M. (Org.). A didática em questão. 3. ed. Petrópolis: Vozes, 1985. p. 12-22.

CANDAU, V. M. A didática e a relação forma/conteúdo. In: CANDAU, V. M. (Org.). Rumo a uma nova didática. Petrópolis: Vozes, 1995. p. 26-32.

DEBORD, G. A sociedade do espetáculo: comentários sobre a sociedade do espetáculo. Rio de Janeiro: Contraponto, 1997.

ERIN BROKOVICH: uma mulher de talento (Erin Brokovich). Produção de Danny DeVito, Stacey Sher, Michael Shamberg, Gail Lyon e John Hardy. Direção de Steven Soderbergh. Estados Unidos, 2000. 1 DVD (130 min), color. son.

FERREIRA, S. da C. Professores e professoras nos filmes, história e papéis sociais. Práxis Educativa, Ponta Grossa, v. 4, n. 1, p. 85-96, 2009.

FERRO, M. Cinema e história. Rio de Janeiro: Paz e Terra, 1992.

FRESCHI, M. As percepções docentes sobre a dimensão metodológica no processo ensino-aprendizagem. Práxis Educativa, Ponta Grossa, v. 3, n. 2, p. 149-157, 2008. 
LEFF, E. Saber ambiental. Petrópolis: Vozes, 2001a.

LEFF, E. Epistemologia ambiental. São Paulo: Cortez, 2001b.

LEFF, E. Complexidade, racionalidade ambiental e diálogo de saberes. Educação e Realidade, v. 34, n. 3, p. 17-24, 2009.

LOUREIRO, C. F. B. Complexidade e dialética: contribuições à práxis política e emancipatória em educação ambiental. Educação \& Sociedade, Campinas, v. 26, n. 93, p. 1473-1494, 2005.

MASCARELLO, F. (Org.). História do cinema mundial. Campinas: Papirus, 2006. METZ, C. A significação no cinema. São Paulo: Perspectiva, 1972.

MONTEIRO, F. G. C. A produção cinematográfica em sala de aula: um outro olhar para o fazer histórico. Revista História Hoje, São Paulo, v. 3, n. 7, p. 1-12, 2005. MUDANÇA de clima, mudança de vidas. Produção e direção Greenpeace Brasil. Brasil, 2006. 1 DVD (51 min), color., son.

NAPOLITANO, M. Como usar o cinema na sala de aula. São Paulo: Contexto, 2009.

O DIA depois de amanhã. The day after tomorrow. Produção de Roland Emmerich e Mark Gordon. Direção de Roland Emmerich. Estados Unidos, 2004, 1 DVD (124 m), color. son.

OLIVEIRA, P. S.; NASCIMENTO, M. C.; BIANCONI, M. L. Mudanças conceituais ou comportamentais? Ciência e Cultura, São Paulo, v. 57, n. 4, p. 1-4, 2005.

OS SIMPSONS: o filme (The Simpsons movie). Produção de James L. Brooks, Matt Groening, Al Jean, Mike Scully e Richard Sakai. Direção de David Silverman. Estados Unidos, 2007. 1 DVD (83 min), color. son.

RODRIGUES, G. S. S. C.; COLASANTI, M. T. M. Educação ambiental e as novas tecnologias de informação e comunicação. Sociedade e Natureza, Belo Horizonte, v. 20, n. 1, p. 51-66, 2008. 
RODRIGUEZ, V. A. El cine por una educación ambiental. Educação e Realidade, v. 34, n. 3, p. 133-145, 2009.

ROSSO, A. J. A distância entre o projeto da educação ambiental e a forma como se efetiva o ensino de Ciências. In: GUERRA, A. F. S.; TAGLIEBER, J. E. (Org.). Educação ambiental: fundamentos, práticas e desafios. ltajaí: Universidade do Vale do ltajaí, 2007a. p. 125-141.

ROSSO, A. J. Avaliação dos significados atribuídos pelos estagiários à metodologia e prática de ensino de biologia. Práxis Educativa, Ponta Grossa, v. 2, n. 2, p. 131-144, 2007b.

ROSSO, A. J. Ensaio teórico-empírico e questões sobre a formação docente, leitura da escola e letramento. In: PRADO, E. M.; SOUZA, M. A. de; FERREIRA, N. S. C. (Org.). Educação em debate. Curitiba: UTP, 2009. p. 135-144.

SAUVÉ, L. Uma cartografia das correntes em educação ambiental. In: SATO, M.; CARVALHO, I. C. M. (Org.). Educação ambiental: pesquisa e desafios. Porto Alegre: Artmed, 2005. p. 17-44.

SAVVA, A.; TRIMIS, E.; ZACHARIOU, A. Exploring the links between visual arts and environmental education: experiences of teachers participating in an in-service training programme. International Journal of Art and Design Education, v. 23, n. 3, p. 246-255, 2004.

SILVA, R. L. F.; KRASILSHIK, M. Dimensão ética e política de filmes didáticos de meio ambiente: um estudo com a programação da TV Escola. In: ENCONTRO DE PESQUISA EM EDUCAÇÃO AMBIENTAL, 4., Rio Claro. Anais... Rio Claro: EPEA, 2007.

SILVEIRA, C. H. Filmes sobre surdos: que representações de surdos e de língua de sinais eles trazem? Práxis Educativa, Ponta Grossa, v. 4, n. 2, p. 177-184, 2009.

TAVARES, C.; FREIRE, I. M. Lugar do lixo é no lixo: estudo de assimilação da informação. Ciência da Informação, Brasília, v. 32, n. 2, p. 125-135, 2003. 
TEIXEIRA, F. E. Documentário moderno. In: MASCARELLO, F. (Org.). História do cinema mundial. Campinas: Papirus, 2006. p. 143-155.

TURNER, G. Cinema como prática social. São Paulo: Summus, 1997.

UMA VERDADE inconveniente (An Inconvenient Truth). Produção de Lawrence Bender, Scott Z. Burns e Laurie David. Direção de Davis Guggenheim. Estados Unidos, 2006. 1 DVD (94 min), color. son.

VÁSQUEZ, A. S. Ética. 23. ed. Rio de Janeiro: Civilização Brasileira, 2002.

Recebido: 27/07/2010

Received: 07/27/2010

Aprovado: 01/11/2010

Approved: 11/01/2010 